\title{
Lírica e Clínica: os Cadernos de Paul Valéry E O PRoJeto de SigMund FREUd
}

ROBERTO ZULAR

Universidade de São Paulo

\section{Resumo}

Tendo como pano de fundo as condições históricas de possibilidade da confluência entre poesia e clínica médica, especialmente quanto ao tratamento objetivo da própria subjetividade, o presente artigo estabelece pontos de contato entre os Cadernos de Valéry e o Esboço de uma psicologia científica de Freud, escritos na mesma época.

Palavras-chave

Valéry; Freud; Foucault; Projeto; Cadernos.

\begin{abstract}
Against the backdrop of the historical conditions of possibility of a convergence between poetry and clinical medicine, particularly regarding the objective treatment of one's subjectivity, the paper establishes contact points between Valéry's Notebooks and Freud's Project for a psychology, texts written in the same period.
\end{abstract}

Keywords

Valéry; Freud; Foucault; Projet; cahier.

O poeta Paul Valéry (1871-1945) e o médico Sigmund Freud (1856-1939) empreenderam no final do século XIX projetos que tocam em questões muito semelhantes, especialmente no que diz respeito à busca de um conhecimento objetivo do funcionamento da subjetividade. Fixado esse eixo, mesmo que se levem em conta as diferenças do estatuto científico (e ficcional) e da posição que ocupam no conjunto das obras de cada um, a aproximação entre os Cadernos de Valéry e o Projeto de uma psicologia científica de Freud se impõe não só por aquilo que dá a ver, como também pelo questionamento das condições históricas de possibilidade da constituição de um campo epistemológico comum. Afinal, a que se deve a convergência de interesses entre um poeta e um médico no final do século XIX, levados, como foram, por problemas internos a suas próprias especialidades?

$\mathrm{Na}$ tentativa de responder a essa questão, o presente artigo parte dos mal-entendidos sobre a relação de Valéry com a psicanálise (tendo como polo, não por acaso, o médico e poeta André Breton), passa por uma análise da historicidade das questões comuns a ambos os campos (a relação entre clínica e lírica, o descompasso entre conhecimento objetivo e evidências perceptivas e os limites da constituição das esferas do público e do privado) para finalmente chegar à análise comparativa de alguns pontos específicos.

\section{Valéry entre a psicanálise e o surrealismo}

A aparente contradição entre as críticas de Valéry à psicanálise e número significativo de trabalhos que o aproximam de Freud deve-se, em boa medida, à publicação póstuma de seus Cadernos. Nesses escritos, iniciados em 1894, descobriu-se que a recusa valeriana se pautava por teorias próprias sobre a consciência, o sonho e o funcionamento mental. Sabemos 
hoje, também, que essas críticas se dirigiam a idéias de Freud recebidas em segunda mão e requentadas por uma série de mal-entendidos que acompanharam a divulgação da psicanálise.

A recusa de Valéry ganha ainda outro tempero quando associada à estreita relação entre psicanálise e surrealismo, importante responsável pela introdução de Freud na cultura francesa. É que Valéry, inicialmente tutor de André Breton (então um estudante de medicina candidato a poeta), passa por um progressivo desentendimento sobretudo quando entram em jogo questões como o sonho e a associação livre. Na parte da correspondência entre os dois depositada na Biblioteca Nacional da França - um dos documentos mais interessantes do fundo Valéry - é evidente o quanto Valéry parecia repetir com Breton, com papéis trocados, a sua relação com Mallarmé. Mas o século XX não era o melhor momento para configuração de relações mestre/discípulo e nem Breton tinha lá muito jeito para aprendiz de feiticeiro.

Breton compartilha com Valéry desde seus primeiros poemas e questões de poética até a "descoberta" da escrita automática. Nesse momento, acirram-se as desavenças, a "alegria do pleno desacordo" como consta na dedicatória de Breton ao exemplar do manifesto surrealista da biblioteca de Valéry. Creio que o ponto central desses desentendimentos encontra-se no impasse gerado em torno da maquinaria supostamente inconsciente da associação livre proposta como método de escrita pelo surrealismo. Somada à aversão de Valéry a manifestos e a grupos literários, podemos resumir a posição valeriana como se ele dissesse a Breton: seu método é interessante, eu também faço isso, mas depois é preciso escrever o poema.

O debate em torno do papel da associação livre na fatura do poema, assim como a relação de Valéry com a psicanálise apontam para uma forte relação entre poesia e funcionamento mental. Trata-se, na perspectiva aqui adotada de um desdobramento da relação entre lírica e reflexividade - um dos pontos nevrálgicos da poesia moderna desde seu início com o primeiro romantismo alemão. Na empreitada valeriana, o caráter reflexivo se escora na constituição de um conhecimento objetivo da subjetividade, na busca de um sistema que desse conta de todos os procedimentos (psíquicos, perceptivos, lógicos, formais etc.) implicados na prática poética. Em que pesem as diferenças e o alcance, os caminhos do jovem Valéry se aproximam dos de Breton especialmente no modo pelo qual o questionamento da poesia se desdobra numa teoria do próprio funcionamento mental, ainda que, para tanto, Valéry tenha abandonado a escrita poética e desde 1894 se dedicasse quase que exclusivamente à construção dessa teoria.

Nessa mesma época, Freud também percorria um caminho inusitado para um neurologista que o levara da clínica médica a uma teoria do funcionamento mental dissociada de explicações puramente biológicas. O Projeto de uma psicologia científica marca bem essa passagem e em mais de um ponto se aproxima dos Cadernos de Valéry, paralelo no qual pautaremos nossa análise que se iniciará, contudo, na aproximação entre clínica e lírica proposta por Foucault.

\section{Clínica e lírica}

Para Foucault, a experiência clínica ocupa importante papel na constituição das ciências humanas, importância não apenas de cunho metodológico, mas por trazer a "possibilidade do indivíduo ser ao mesmo tempo sujeito e objeto de seu próprio conhecimento, implica que se inverta no saber o jogo da finitude". 329

Ainda salienta Foucault que

essa experiência médica está por isto mesmo aparentada com uma experiência lírica que procurou sua linguagem de Hölderlin a Rilke. Esta experiência, que inaugura o

\footnotetext{
${ }^{329}$ Michel Foucault, O nascimento da clínica, São Paulo, Forense, 1998, p. 227.
} 
século XVIII e de que ainda não escapamos, está ligada a um esclarecimento das formas da finitude, de que a morte é, sem dúvida, a mais ameaçadora e também a mais plena. ${ }^{330}$

Sob a dura lei do limite, da finitude,

a subjetividade terá como destino configurar-se sempre na objetividade que a manifesta e a oculta, que a nega e a funda: "ainda aqui o subjetivo e o objetivo trocam sua figura". O movimento que serve de base ao lirismo do século XIX é, de um modo que à primeira vista pode parecer estranho, o mesmo pelo qual o homem tomou conhecimento objetivo de si próprio.

Assim, não é de espantar que em um dado momento as preocupações de um poeta e um médico convirjam na tentativa de elucidar o funcionamento da mente.

Nesse passo, é revelador o fato de o próprio Valéry não ter escapado à tentação de atravessar as fronteiras do hospício. ${ }^{331}$ Mais do que isso, no primeiro dos seus Cadernos - intitulado Journal de bord [Diário de bordo] - pode ser encontrada uma lista de artigos onde constam possíveis temas como "A variabilidade do indivíduo (histeria, imagens dominantes etc.)" ou ainda "The men known by inconscient reactions and mistakes".

A curiosidade de Valéry demonstra bem o interesse despertado por esses "fenômenos psíquicos", especialmente como um modo particular de produção de idéias. Pode-se até mesmo imaginar que ele as tenha relacionado com a poesia de Rimbaud - a qual exigia novos parâmetros para ser compreendida - e que essa experiência tenha reforçado a necessidade de uma compreensão e controle do modo desse funcionamento desregrado da linguagem (e dos sentidos) cuja problemática é muito próxima daquela enfrentada por Freud ao tentar estabelecer um discurso racional sobre o funcionamento patológico do aparelho psíquico. ${ }^{332} \mathrm{O}$ próprio Valéry no Journal de bord revela "momentos de delírios de grandeza, de delírios criminais, de delírio depressivo - uma turba de situações ou de desejos - encontram-se, em graus diversos, em todos os homens". ${ }^{333}$

Antes, porém, de entrar nesse debate, voltemo-nos um pouco para a histeria, em especial porque a distância entre as causas e os efeitos de sua constituição aproxima-se em muito da cisão entre cálculo e percepção do mundo em torno da qual se debatia a matemática.

\section{Histeria e matemática}

\footnotetext{
${ }^{330}$ Idem, ibidem, p. 228.

${ }^{331}$ Em uma página do dossiê de suas "notes anciennes" intitulada "visite à la clinique des aliénés à Montpellier", circa 1893, encontra-se uma série de anotações de uma aula do Prof. Mairet sobre "loucura de perseguição", entendida como uma doença da inteligência, causada por alucinações e pela crença de que os outros adivinham pensamentos do doente, tendo como efeito uma total perversão dos sentidos e estando ligada a delírios de grandeza. Há em seguida duas anotações de discursos de pacientes. Um jovem oficial com "idéias de perseguição", o qual Valéry frisa que durante o dia não apresentava nenhum sintoma e de que suas "idéias" eram de fato falsas alucinações. Segue-se o relato de uma mulher constituído pela transcrição de seu discurso no qual as idéias encontram-se totalmente desconectadas (aparentemente não parece ser o mesmo tipo de problema do oficial).

${ }^{332}$ Essa hipótese será desenvolvida pontualmente um pouco adiante.

${ }^{333}$ Paul Valéry, Cahiers, 1894-1914, Edição "integral” organizada por Nicole Celeyrette-Pietri e Judith Robinson Valéry, Paris, Gallimard, 1987, p. 74. Embora fundamental, é importante ressaltar os limites dessa edição. Nesse sentido, ver o primeiro capítulo de minha tese de doutorado intitulada No limite do país fértil - Os escritos de Paul Valéry entre 1894 e 1898, defendida no Departamento de Letras Modernas da FFLCH-USP em agosto de 2001 (tradução minha).
} 
O caráter ambíguo dado à histeria, entre doença e mascaramento, aponta com acuidade a problemática levantada pelo seu tratamento, em especial a desconexão aparente entre sintomas e causas. Essa distorção na lei da causalidade é responsável pela ruptura dos métodos de praxe da clínica médica e será, como é sabido, responsável pela formulação da teoria psicanalítica através da qual se compreendeu que "o recalque tende essencialmente a separar o afeto da representação".

Tendo em vista a preocupação histórica de minha abordagem, limitar-me-ei a abordar a histeria dentro da perspectiva traçada por Freud em artigo sobre o tema de 1888. Nesse artigo, Freud procura defini-la "pelo conjunto de sintomas em que aparece", 334 não sem passar por uma consideração "histórico-cultural" dada pela própria etimologia da palavra (do grego: matriz, útero), fazendo um pequeno relato de sua conceitualização nos primórdios da medicina como afecção do aparelho sexual feminino e pela significação atribuída na Idade Média como "possessão pelo demônio e bruxaria".

Rechaçando "a idéia de que haveria na base da histeria uma possível perturbação orgânica", Freud esmiuça a sintomatologia histérica em cinco pontos: 1) ataques convulsivos: principalmente pressão no epigástrio, opressão na garganta, martelagem nas têmporas, zumbido nos ouvidos. O ataque propriamente é descrito em três fases, quais sejam, um ataque epilético comum, depois os movimentos de grande envergadura e, finalmente, atitudes passionais; 2) zonas histerógenas: lugares hiper-sensíveis do corpo cuja estimulação leve desencadeia um ataque; 3) perturbações da sensibilidade: anestesia ou hiperestesia dos sentidos, sobretudo anestesia da pele; 4) perturbações da atividade sensorial: alterações da sensibilidade, problemas de visão (por exemplo, não ver cores), surdez e mesmo anestesia do paladar e do olfato; 5) paralisias: diferente da anestesia, causa perturbações de mobilidade (e não de sensibilidade).

Cumpre ressaltar a ênfase de Freud, uma vez elidida a existência de uma causa orgânica, na relação entre os sintomas e a possibilidade de tratamento pela "sugestão hipnótica" e, sobretudo, a idéia de que se trata "de um influxo do aparelho psíquico sobre os processos físicos do organismo", "um excedente de excitação no sistema nervoso, o qual se exterioriza ora inibindo, ora estimulando, e é deslocado com grande facilidade dentro do sistema nervoso". Dentro desse quadro, fica claro que a hipótese freudiana - realçada no resumo final pela expressão "provavelmente com formação de um excedente de estímulo" (d. m.) - opera em um vazio de causas, colocando em xeque os métodos da clínica anatomopatológica, acentuando o caráter quantitativo e a freqüência com que os sintomas parecem desconectados da própria pessoa "em que" ocorrem: "muitos dos enfermos contam entre as pessoas mais amáveis, de vontade mais firme e mente mais clara, e sentem nitidamente as exteriorizações de sua enfermidade como algo alheio ao seu ser". ${ }^{335}$ A personagem cindida de Dr. Jekyll e Mr. Hyde não eram muito diferentes dos pacientes de Freud.

A curiosidade sobre o que se passava nos hospícios, como vimos com Valéry, já ultrapassara em muito os limites médicos e se tornara questão crucial de sua época. Para ficarmos em alguns exemplos franceses, lembremos que a questão é central no conto "Le Horla", de Maupassant, freqüentador do "espetáculo" dado pelas histéricas no palco

\footnotetext{
${ }^{334}$ Sigmund Freud, Obras completas, Buenos Ayres, Amorrortu,1976, v. I, p. 45.

${ }^{335}$ Vale ainda notar nesse artigo pelo menos três antecipações das formulações teóricas que conduzirão Freud à psicanálise: 1) a base psíquica da histeria, "as perturbações psíquicas, nas quais certamente algum dia se descobrirão as alterações características dessa enfermidade"; 2) a importância da sexualidade, "se deve admitir que umas constelações funcionais relativas à vida sexual desempenham um grande papel na etiologia da histeria (assim como de todas as neuroses)"; e 3) a busca da "pré-história psíquica do padecer", fazendo o paciente "confessar a ocasião psíquica a partir da qual foi gerada a perturbação correspondente".
} 
das aulas públicas de Charcot, assim como em outro palco, nas atuações de Sarah Bernardt. Como esclarece Elizabeth Roudinesco, a atriz evoca com seus gestos

as convulsionárias da Salpêtrière; ela transporta para os palcos as interrogações de sua época sobre a ambivalência da sexualidade humana. A atriz é a imagem do 'sujeito dividido' da síndrome histérica: homem afeminado em busca de uma identidade masculina, mulher fálica à procura de uma feminilidade sem disfarces $[\ldots]^{336}$

Curiosamente, toda a irredutível dualidade envolvida na compreensão e no tratamento da histeria assemelha-se àquela referente às ciências exatas, em especial à matemática, quanto à relação entre as construções teóricas e a observação. Nas palavras de Hobsbawm,

o processo de divórcio entre ciência e intuição pode talvez ser ilustrado através do exemplo extremo da matemática. Em algum momento de meados do século XIX, o progresso do pensamento matemático começou a gerar resultados conflitantes com o mundo real $[\ldots .$.$] como também resultados que pareciam conflitantes até aos$ matemáticos. $^{337}$

Na tentativa de estabelecer "a natureza da relação entre o jogo matemático e a estrutura do mundo real" ${ }^{338}$ os matemáticos se dividiram entre formalistas (que acreditavam em uma "verdade matemática objetiva") e a escola dos intuitivos (que rejeitavam o formalismo, "inclusive, às custas de abandonar os próprios triunfos do raciocínio matemático",339).

A confluência inusitada entre as questões envolvidas no tratamento da histeria e nas questões matemáticas pode ser flagrada por todo o Journal de bord em que, lado a lado às anotações concernentes ao funcionamento da mente, à histeria e às ações inconscientes, encontramos cálculos e reflexões sobre geometria e álgebra.

Retomando Hobsbawm, no debate entre formalistas e "intuitivos" configuravase a "falência das antigas vinculações entre matemática e a percepção do mundo". Nesse sentido, tanto o desenvolvimento da matemática quanto o da histeria enfrentavam a mesma limitação na descrição do visível; o mesmo distanciamento entre as causas aparentes e as conclusões teóricas.

Esse entrelaçamento de preocupações ao desdobrar-se sobre o pensamento, em especial na loucura (não mais entendida como algo simplesmente não-racional ${ }^{340}$ ), efetua ainda um curto-circuito nas relações entre ciências humanas e exatas, curtocircuito este em que se encontram o Projeto de uma psicologia de Freud e também os Cadernos de Valéry: a objetividade buscada na matemática depara com as questões epistemológicas dessa e legitima a construção de uma teoria distanciada das evidências perceptivas.

Um fator importante nesse percurso de criação teórica é a instauração de um novo lugar para a inter-relação entre as esferas do público e do privado. Todo o desenrolar dessa aproximação com as ciências exatas deu-se em âmbito estritamente privado: quer pelo fato dos textos não terem sido publicados quer na correspondência de cunho eminentemente científico entre Freud e Fliess e entre Valéry e Pierre Feline.

\footnotetext{
${ }^{336}$ Elizabeth Roudinesco História da psicanálise na França, Rio de Janeiro, Jorge Zahar, 1999, p. 23.

${ }^{337}$ Eric Hobsbawm, A era dos impérios, trad. Sonia Maria Campos e Yolanda Steidel de Toledo, Rio de Janeiro, Paz e Terra, 1988, p. 341.

${ }^{338}$ Idem, ibidem.

${ }^{339}$ Idem, ibidem.

${ }^{340}$ Roberto Machado, Foucault, a filosofia e a literatura, Rio de Janeiro, Jorge Zahar Editor, 2000.
} 


\section{A privação do público}

No trecho da Introdução ao método de Leonardo da Vinci que se refere expressamente aos manuscritos do próprio Leonardo e de Pascal, Valéry enfatiza os recuos, negações, sorrisos e contrações diante de uma idéia. Em seguida, ele esclarece: os loucos o fazem diante de todos "les fous s'y livrent devant tout le monde". ${ }^{441}$ Essa diferenciação não é totalmente ingênua e nos obriga a algumas reflexões.

Ao enfatizar o domínio privado desses escritos, aproximamo-nos das conclusões de Jean-Louis Lebrave a respeito do século XIX no qual, segundo o autor, ocorre o apogeu do texto impresso moderno. ${ }^{342}$ "De um lado, isola a esfera privada da escritura e a atividade de produção: é o reino da escritura manuscrita, geralmente abundante, até anárquica. Em oposição, encontra-se o domínio público dos destinatários, leitores múltiplos de um texto sempre idêntico". 343

Atentando à singularidade e às consequiências dos modos de produção da escrita no decorrer da história, a ênfase na divisão apresentada antes permite entender a importância dos manuscritos dessa época: eles são o lugar privilegiado do erro, da liberdade de errar, da errância. Lembremos que a maior parte da obra de Stéphane Mallarmé chegou até nós apenas como manuscritos. Eles são o lugar de formulação de hipóteses distanciadas da necessidade de responder a questões determinadas, aos temas da moda, aos discursos institucionais, em suma, às teias que o poder disciplinar vai tecendo sobre as práticas de produção.

Nessa perspectiva, os manuscritos modernos correspondem a uma forma de subjetividade forjada no limite da relação entre público e privado, limite esse, no caso das práticas de produção escrita, que se constitui pelo embate constante entre as infinitas hipóteses possíveis e as sucessivas escolhas que constituem o percurso das práticas de produção, remetendo a escolha final para um outro processo que conduz à publicação do livro.

Torna-se, portanto, aspecto relevante a permanência no âmbito privado do Projeto de uma psicologia e dos Cadernos. Esse fato nos obriga a situá-los no campo do possível, em um espaço conjetural que a sua posterior inclusão como "obra" tende a desrespeitar. A facilidade com que o nosso século, por razões técnicas e ideológicas, atravessa as barreiras do privado e do público, não deve descaracterizar a análise e a particularidade desses escritos, por mais que hoje pareça "arrogante, estranho e deslocado quem se entrega a algo privado sem que nele se possa notar uma orientação para algum fim". 344

Creio que ambos os autores concordariam com Emmanuel Levinas, conforme Pierre Hayat, sobre a importância do traço de um passado que não foi jamais presente. Eles são indicações que não devem conduzir necessariamente a um lugar determinado (como suas publicações fazem crer). É a partir dessa indeterminação que a "objetividade" das ciências exatas vai permitir à teoria ganhar a liberdade do imaginário e que, em um segundo momento, o imaginário teórico ganhe dimensão pública.

Nesse percurso, a correspondência também cumpre um papel decisivo. É a partir da troca de cartas que tanto Freud quanto Valéry vão ser iniciados na busca de uma cientificidade do saber.

Muito já se falou sobre a correspondência entre Freud e Fliess, inclusive quanto à sua importância na constituição da teoria psicanalítica. Em especial no tocante à

\footnotetext{
${ }^{341}$ Paul Valéry, Ouvres, Paris, Gallimard, 1957 v. I, 115.

342 Jean-Louis Lebrave, "La critique génétique: une discipline nouvelle ou un avatar moderne de la philologie?" in Genesis I, Paris, Jean Michel Place, 1992, p. 69.

${ }^{343}$ Idem, ibidem, p. 43.

344 Theodor W. Adorno, Mimina moralia, São Paulo, Ática, 1992, p. 17.
} 
questão da cientificidade, enfoque que nos ocupa neste momento, Erik Porge delineia o alcance com precisão:

De aparecimento relativamente recente e contornos imprecisos, a biologia era um campo que Freud esperava que trouxesse uma certa garantia ou confirmação para o caminho que ele vinha abrindo. Fliess permitiu que ele ligasse seu desejo de ser analista que já se exercia no tocante a seus pacientes - à ciência, por intermédio de uma ciência em devir $[\ldots]^{345}$

Ainda que a correspondência seja bastante diferente daquela entre Freud e Fliess, também há nas cartas de Valéry a Feline um chamado ao outro supostamente representante daquele mundo objetivo. Da parte dessa correspondência que tivemos acesso no acervo da Biblioteca Nacional (tanto passiva quanto ativa), ela se centra na iniciação de Valéry no estudo da matemática, havendo longas discussões sobre soluções de problemas e, curiosamente, uma interessante análise de Feline sobre uma ópera de Wagner. ${ }^{346}$

Respeitadas as diferenças e o alcance das correspondências, importa sobretudo notar, como quer Erik Porge, a importância dessa busca de objetividade e exatidão se configurar no âmbito privado a partir de um chamado ao outro e que, ao contrário do que se poderia esperar, Freud e Valéry usarem essa transferência na articulação de uma esfera mais emocional e audaciosa da compreensão do funcionamento da mente, como fazem prova os Cadernos e o Projeto que passaremos, enfim, a analisar.

\section{Algumas questões paralelas}

Valéry inicia seus Cadernos sob o impacto do eletromagnetismo de Maxwell e, portanto, no campo dos fluxos de energia como modelo para o desenvolvimento de suas idéias. O eletromagnetismo trazia um conceito essencial para Valéry: o espaço não é vazio, mas composto de sistemas de linhas unindo todos os corpos, preenchendo todo o espaço, como as idéias devem estar na mente do "homem de gênio", "Estava reservado a Faraday encontrar na Física o método de Leonardo". ${ }^{447}$ Nas palavras do próprio Maxwell, citadas por Valéry na Introdução, "Faraday via, pelos olhos de seu espírito, linhas de força atravessando todo o espaço onde os matemáticos viam centros de força atuando à distancia".348

O encanto com essa teoria não é fortuito; além do ideal de matematização, o eletromagnetismo dava forma e rigor científico ao funcionamento do "invisível”, enchia de potencialidades o espaço da mente. De uma maneira muito próxima, no modelo neuronal do Projeto, que "supõe como partículas materiais os neurônios", há uma

\footnotetext{
${ }^{345}$ Erik Porge, Freud, Fliess. Mito e quimera da auto-análise, Rio de Janeiro, Jorge Zahar, 1998, p. 33. Não por acaso, comentando a obra de Georges Gusdorf, Le savoir romantique de la Nature, Porge ainda salienta, em estreita consonância com as questões tratadas no Nascimento da clínica que "o termo 'biologia', só foi introduzido no alvorecer do século XIX, na França, em um contexto científico (Xavier Bichat), e na Alemanha, onde fez parte do vocabulário romântico (G. R. Trevianus). A introdução desse termo destinava-se a dar lugar a uma ciência distinta da fisiologia, que levasse em conta a especificidade da força vital (Lebenskraft) imanente à matéria orgânica e incluísse o microcosmo e o macrocosmo no campo unitário de uma inteligibilidade universal. A vida desceu ao seio da matéria como uma essência específica, instituindo uma comunidade de seres vivos. A biologia romântica da Naturphilosophie propôs um novo modelo de saber, do qual não estava ausente o matematismo, sob a forma de números que regeriam a economia interna de um organismo vital".

346 "La musique tu la vois, mais elle - sa voix - ses bras (Elle=Musique Sa voix =livret Ses bras = decors) Voilá l'idée trilogique de Wagner reconstituée".

${ }^{347}$ P. Valéry, Ouvres op. cit., p. 1195.

${ }^{348}$ Idem, ibidem,
} 
ênfase nos processos envolvendo a transformação e quantificação de energia, "processos como estímulo, substituição, conversão, descarga, que ali se podiam descrever, sugeriram de uma maneira direta a concepção da excitação neuronal como quantidades fluentes".

Nos dois autores, há uma tendência à redução de todo o funcionamento do sistema a um princípio simples: em Freud, o "princípio da inércia neuronal enuncia que os neurônios procuram aliviar-se da quantidade", e em Valéry, o "potencial", tendência à igualização, isto é, o funcionamento da mente tende a compor as forças que o compõe, tende a reduzir a uma mínima ação a diferença entre as coisas.

Esses princípios parecem intimamente ligados à noção de entropia (a tendência do sistema à desorganização, à perda constante de energia), a qual por sua vez pode ser associada à pulsão de morte que Freud elaboraria expressamente em Além do princípio do prazer, texto esse que em mais de um aspecto lembra a estrutura do Projeto. Embora não possamos tratar dessa comparação neste momento, saliento que ambos os princípios aproximam-se daquele denominado por Poe como "princípio de repulsão", o qual ele identifica com o universo espiritual em forte consonância com os textos aqui tratados.

Mais do que isso, a redução quantitativa perpetrada por ambos é vista por Valéry de maneira muito próxima ao sistema neuronal de Freud, vez que para esse "todo ato humano é o desarranjo de uma certa ordem inicial, dada, e a aparição de uma nova ordem dita psíquica. Se se negligencia os termos para reter somente a ordem constata-se que é de natureza física, e contém leis quantitativas".

Além disso, Freud utiliza-se da hipótese de que "um neurônio singular é uma cópia do sistema neuronal em seu conjunto", enquanto para Valéry, "uma boa análise psíquica dissecaria finalmente as quantitades imaginárias, os infinitamente pequenos etc.".349

Poderíamos analisar questões sobre a consciência, o sonho, a vigília, a memória, as oscilações entre explicações mecânicas e biológicas, as metáforas econômicas, as considerações sobre uma pragmática do pensamento, mas como intentamos demonstrar como o suposto paradigma científico deu a ambos uma extrema liberdade imaginativa, passarei a desenvolver esse ponto.

Há uma tendência maior em Freud à constituição de uma topologia e em Valéry a uma álgebra que desse conta das operações do espírito. Assim, Freud traça caminhos que constituem o funcionamento do cérebro, onde o "eu" seria uma organização e poderia ser representado "como uma rede de neurônios investidos" que tem por função inibir os processos psíquicos primários. ${ }^{350}$

Para Valéry, "a ciência matemática destituída de suas aplicações tais como a geometria, a aritmética escrita etc. e reduzida à álgebra, isto é, a uma análise das transformações de um ser puramente diferencial, composta de elementos homogêneos é o mais fiel documento das propriedades de agrupamento, disjunção e variação do espírito" Disto decorre a conclusão de que "O 'eu' é uma frequiência - um número entre outro" e portanto passível de ser reduzido a uma álgebra.

Seja topologicamente seja algebricamente, ambos os sistemas propiciam uma facilidade muito grande para se pensar deslocamentos e substituições, procedimentos centrais para ambos. Assim, Freud explica topologicamente o deslocamento das idéias conscientes e inconscientes no sonho, como no famoso caso de "Emma", no qual a parte não visível de um complexo de conexões representa as associações que ficaram reprimidas e que, no entanto, a partir da representação dos vestidos, propicia uma

\footnotetext{
${ }^{349}$ P. Valéry, Cahiers 1894-1914, op. cit., p. 72 (tradução minha).

${ }^{350}$ Para Valéry, até onde pudemos acompanhá-lo, não existe nada que se assemelhe a essa função repressiva interna.
} 
liberação sexual associada à cena de estar em uma mercearia, embora o suposto atentado não apareça no sonho.

De maneira mais esquemática, Freud apresenta o deslocamento das representações no sonho em outro momento: "seja uma representação onírica que se tornou consciente; ela conduz para $\mathrm{B}$, mas no lugar de $\mathrm{B}$ encontra-se $\mathrm{C}$ na consciência, e na verdade porque [ela] está no caminho entre B e uma ocupação simultânea, de outro tipo e que, além disso, ela mesma é não consciente".

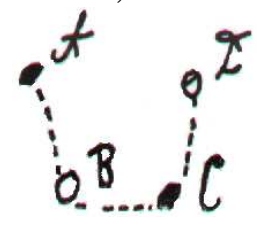

Em seguida, o autor do Projeto explicita que "o desejo na verdade não é tornado consciente", apenas alucina-se o seu cumprimento, "a articulação intermediária, tem de ser inferida" ${ }^{351}$ Isto é, a relação entre desejo e cumprimento nunca é dada, é preciso inferi-la. Essa inferência equivale ao processo de condensações de que fala Valéry na obra de Rimbaud, em que os efeitos das coisas vão se condensando, de maneira alucinada, em determinados verbos.

Neste ponto, embora no Journal de bord haja uma ênfase em análises algébricas, vale a pena resgatar uma nota de 1892, na qual Valéry procura estabelecer a lógica das construções de Rimbaud de uma maneira muito próxima do "complexo" freudiano:

Em A[rtur] R[imbaud], o milagre é a atração não entre as qualidades das coisas ou de seus seres - [mas] entre os efeitos totais produzidos por essas coisas

Visão direta da reação

"Chez A[rthur] R[imbaud], le miracle est l'attraction non parmi les qualités des choses ou leurs êtres - parmi les effets totaux produits par ces choses.

vision directe de la réaction

condensação no verbo.

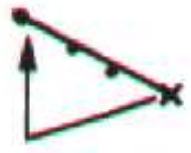

substituição perene da personalidade pelo objeto do qual se fala

relatividade absoluta das notações

A metáfora de S[téphane] M[allarmé] é inferior, pode-se transportar, contar

Fora do poema

substitution toujours de la personnalité à l'objet dont il est parlé

relativité absolue des notations.

La métaphore de S[téphane] M[allarmé] est inferieure, se pouvant transporter, raconter hors du poème". 352

Por fim, retomando nosso paralelo, resta salientar o valor desses métodos especialmente para a análise do funcionamento dos processos psíquicos sem apelar a uma instância superior. Ambos se deparam com a "tarefa inglória de construir os princípios organizadores da experiência a partir da própria experiência". ${ }^{353}$ Neste limite,

\footnotetext{
${ }^{351}$ Sigmund Freud, Projeto de uma psicologia, trad. Osmyr Faria Gabbi Jr,. Rio de Janeiro, Imago, 1995, p. 53

${ }^{352}$ Robinson-Valéry, Judith, Rimbaud, Valery et La incohérence harmonique, Paris: Minad, 1979, p. 378.

${ }^{353}$ S. Freud, Projeto de uma psicologia, op. cit., nota 153, p. 146.
} 
Freud faz intervir os neurônios do tipo w, responsáveis pela consciência e que funcionam como uma percepção interior ao sistema. Ao seu turno, Valéry constantemente se ancora na hipótese de um operador invisível articulando os atos de conhecimento.

\section{Duas paralelas se encontram no infinito?}

Estabelecido o paralelo, cabe, enfim, tentar entender o papel desenrolado por essa busca de objetividade na obra dos dois autores. Afinal, abandonadas, como de fato o foram, as análises de caráter quantitativo, o que resta desses projetos?

Primeiramente, a experiência de um objetivo impossível, mas sempre necessário, no horizonte. Em especial para Valéry, entre mobilidade e fixidez, a importância dos interstícios. "Ce qui n'est pas fixé n'est rien. Ce qui est fixé est mort". Dessa filosofia de antíteses, Adorno conclui "alors qu'elles restent là - as antíteses - non conciliées, la pensée exprime sa propre limite: la non-identité de l'objet avec son concept, qui doit exiger cette identité et en même temps comprendre qu'elle est impossible". ${ }^{354}$

A aproximação da impossibilidade de um universo objetivo, a limitação mesma dessa objetividade, permitiu tanto a Valéry quanto a Freud vislumbrarem o limite, não deles como indivíduos, mas da própria condição humana.

Mesmo porque, essa limitação, essa carência continuada do humano encontra na matemática um lugar dos mais privilegiados para pensá-la: a matemática possibilita a representação da falta, a atribuição a ela de um lugar operatório, a partir de uma das mais importantes invenções da humanidade: o zero. Como mais tarde afirmaria Valéry, "Zéro n'est pas rien, il est encore une valeur, il affirme qu'il n'est ni 1, ni 2, ni infini. Il est un nombre qui a son rôle: un opérateur" (XXVII, 571). "Comme le zéro joue aussi le rôle d'une quantité, ainsi le Moi joue aussi le rôle d'une chose, d'un sujet." "355

A outra face da busca dessa representação da falta, a álgebra tão buscada por Valéry, é a compreensão de que não há uma "substância" do pensamento: só se pode captá-lo pelas interconexões que se formam e que simultaneamente o formam. Assim, não é estranho que no viés dessa matematização e antiteticamente a ela, Valéry e Freud estivessem tão sensíveis à articulação entre a experiência psíquica e o universo simbólico no qual ela se inscreve, isto é, de que, nas palavras de Renato Mezan, Freud seja visto como um "pensador da cultura" e Valéry, um poeta para quem a literatura podia ser considerada "questão de Estado" e o percurso de criação, um "campo de batalha".

Assim, vale repetir que, sob o ideal de cientificidade, desvela-se um diálogo ininterrupto com inúmeros interlocutores (incluindo Fliess e Feline) e um contínuo pensar na experiência do mundo. Não se pode, pois, crer na existência de uma autoanálise ou de um autoconhecimento, o que encobriria um longo percurso de formulações hipotéticas na constituição do imaginário teórico dos seus autores.

Freud:

$$
\text { Voltando mais uma vez ao livro de Porge, }{ }^{356} \text { veja-se o seguinte comentário de }
$$

minha auto-análise continua parada. E agora compreendo a razão disso. É que só posso analisar a mim mesmo servindo-me de conhecimentos objetivamente adquiridos (como em relação a um estranho); a verdadeira auto-análise é de fato impossível, caso contrário não existiria doença.

\footnotetext{
354 Theodor W. Adorno, "Les écarts de Valéry", in Notes sur la litérature, Paris, Flamarion, p. 118.

${ }^{355}$ Nicole Celeyrette-Pietri, Valéry et le moi, p. 35

${ }^{356}$ Erik Porge, Freud, Fliess. Mito e quimera da auto-análise, op. cit., p. 31.
} 
A busca de objetividade, de "conhecimentos objetivamente adquiridos", formula-se na liberdade das hipóteses desenvolvidas no Projeto e nos Cadernos, sobre os quais - no limite dos quais - Freud e Valéry desenvolveram muitos de seus trabalhos posteriores. 